Check for updates

Cite this: RSC Adv., 2020, 10, 3472

\title{
Gas-phase molybdenum-99 separation from uranium dioxide by fluoride volatility using nitrogen trifluoride
}

\author{
Bruce K. McNamara, (D) *a Matthew J. O'Hara, (D) a Richard A. Clark, (D) \\ Samuel S. Morrison, (D) ${ }^{a}$ Chuck Z. Soderquist (D) ${ }^{a}$ and Randall D. Scheele (D) ${ }^{b}$
}

Production of the important ${ }^{99 \mathrm{~m}} \mathrm{Tc}$ medical isotope parent, molybdenum-99 ( $\left.{ }^{99} \mathrm{Mo}\right)$, via the fissioning of high- and low-enriched uranium (HEU/LEU) targets followed by target dissolution in acid and solutionphase purification of ${ }^{99} \mathrm{Mo}$ is time-consuming, generates quantities of corrosive radioactive waste, and can result in the release of an array of radionuclides to the atmosphere. An alternative ${ }^{99}$ Mo purification method has been devised that has the potential to alleviate many of these issues. Herein, we demonstrate the feasibility of a rapid $\mathrm{Mo} / \mathrm{Tc}$ gas-phase separation from $\mathrm{UO}_{2}$. The results indicate that volatile [ $\left.{ }^{99} \mathrm{Mo}\right] \mathrm{Mo}$ can be captured downstream of the reacted solid mixture on a column bed (trap) of alumina; the majority of the captured $\left[{ }^{99} \mathrm{Mo}\right] \mathrm{Mo}$ can be subsequently eluted from the alumina trap with a few millititers of water. $>1.0 \times 10^{5}$ single pass decontamination of $U$ and the collected $\left[{ }^{99}\right.$ Mo]Mo product is demonstrated. This simple thermo-fluorination technique has the potential to provide a rapid methodology for routine ${ }^{99}$ Mo production.

Received 7th December 2019

Accepted 7th January 2020

DOI: 10.1039/c9ra10270a

rsc.li/rsc-advances for the volatile products. ${ }^{\mathbf{1 0 , 1 1}}$ Regardless of the exact process used, fluorination requires the use of rigorously closed reactor and trapping systems. These systems are thus more suited to complete trapping of volatile fission products than the liquid digestion processes currently in use.

The usefulness of $\mathrm{NF}_{3}$ for volatility separations is related to its slightly lower thermal reactivity compared to more potent fluorinating reagents. The lower reactivity of $\mathrm{NF}_{3}$ allows for volatility of a reduced set of fission products, in particular, Mo and Tc, without volatilization of $\mathrm{U}, \mathrm{Np}$ and $\mathrm{Pu}$. The basis for the separations is the formation of thermally stable, nonvolatile $\mathrm{UO}_{2} \mathrm{~F}_{2}$ produced as the first product in the fluorination of $\mathrm{UO}_{2}$ (eqn (1)), or of $U_{4}$ in the case of the $U$ metal fluorination (eqn (2)):

$$
\begin{gathered}
\mathrm{UO}_{2}+\frac{2}{3} \mathrm{NF}_{3} \stackrel{\left(450-500^{\circ} \mathrm{C}\right)}{\longrightarrow} \mathrm{UO}_{2} \mathrm{~F}_{2}+\frac{1}{3} \mathrm{~N}_{2} \\
\mathrm{U}^{0}+\frac{4}{3} \mathrm{NF}_{3} \stackrel{\left(90-120^{\circ} \mathrm{C}\right)}{\longrightarrow} \mathrm{UF}_{4}+\frac{2}{3} \mathrm{~N}_{2}
\end{gathered}
$$

The fluorinated solid matrix formed per eqn (1) or (2) can be further reacted with $\mathrm{NF}_{3}$ to extract volatile fluorides without formation of gaseous $\mathrm{UF}_{6}$. The onset temperature for the conversion of $\mathrm{UO}_{2} \mathrm{~F}_{2}$ to $\mathrm{UF}_{6}$ is usually near $500{ }^{\circ} \mathrm{C}$, but can be stalled nearly completely by lowering the $\mathrm{NF}_{3}$ concentration to 1 or $5 \%$ in Ar. ${ }^{12}$ Similarly, in a metal target the conversion of $\mathrm{UF}_{6}$ from $\mathrm{UF}_{4}$ can be considerably slowed using reduced temperature or lower $\mathrm{NF}_{3}$ concentrations. ${ }^{13}$ This feature of the reactions 
allows for gaseous leaching of the solid U-bearing sample for the time required to volatilize lower boiling point components (such as ${ }^{99} \mathrm{Mo} /{ }^{99 m} \mathrm{Tc}$ ) that are generally shown to be rapidly separated at or below $400{ }^{\circ} \mathrm{C}$. Separation and recovery of volatile $\mathrm{MoF}_{6} / \mathrm{TcF}_{6}$ from other fission products has been demonstrated by use of selective sorbents, such as solid $\mathrm{MgF}_{2} \cdot{ }^{\mathbf{1 4}}$

High temperature oxidation of irradiated $\mathrm{U}$ has been widely cited as being effective at removal of gaseous fission products such as Xe and $\mathrm{Kr}^{15}$ This is more rapidly and completely realized by the lattice disruption of the $\mathrm{U}$ solid, as induced by fluorination (eqn (2) and (3)). Fluorination using $\mathrm{NF}_{3}$ will volatilize $\mathrm{Nb}, \mathrm{Mo}, \mathrm{Sb}, \mathrm{Tc}, \mathrm{Te}^{\mathbf{1 6 , 1 7}}$ and I from a solid matrix at or below $\sim 400{ }^{\circ} \mathrm{C}$. Ru will be released near $500{ }^{\circ} \mathrm{C} .{ }^{18}$ Rhodium, $\mathrm{Pd}^{18}$ and $\mathrm{Pu}^{17}$ do not form volatile fluorides using $\mathrm{NF}_{3}$ as the fluorination reagent. Americium, ${ }^{19}$ the lanthanides, and the Group I and II elements do not form volatile fluorides using any fluorinating reagent. $^{20}$

After down-stream capture of the volatile fission products has been performed, uranium can be recovered as gaseous $\mathrm{UF}_{6}$ per eqn (3) or (4), leaving the lanthanides, $\mathrm{Pu}, \mathrm{Am}$, and the other non-volatiles in the reactor furnace.

$$
\begin{gathered}
\mathrm{UO}_{2} \mathrm{~F}_{2}+\frac{4}{3} \mathrm{NF}_{3} \stackrel{\left(300-430^{\circ} \mathrm{C}\right)}{\longrightarrow} \mathrm{UF}_{6}+\frac{2}{3} \mathrm{~N}_{2} \\
\mathrm{UF}_{4}+\frac{2}{3} \mathrm{NF}_{3} \stackrel{\left(>500^{\circ} \mathrm{C}\right)}{\longrightarrow} \mathrm{UF}_{6}+\frac{1}{3} \mathrm{~N}_{2}
\end{gathered}
$$

Here, we show that a gas/solid leaching process using $\mathrm{NF}_{3}$ to recover ${ }^{99} \mathrm{Mo} /{ }^{99 \mathrm{~m}} \mathrm{Tc}$ from a simulated $\mathrm{UO}_{2}$ target has a sound empirical basis that promises rapid, single pass, high yield recovery of ${ }^{99} \mathrm{Mo} /{ }^{99 m} \mathrm{Tc}$.

\section{Experimental}

\subsection{Reagents and materials}

Mo metal, $\mathrm{MoO}_{2}$ and $\mathrm{MoO}_{3}$ were purchased from Alfa Aesar (Haverville, MA). Deionized water from a Barnstead E-Pure (Thermo Fisher, Waltham, MA) water purification system was $18.0 \mathrm{M} \Omega \mathrm{cm}$. Activated alumina spheres $(0.125$ inch dia.) were purchased from Delta Adsorbents (Roselle, IL). The sample and reference pans used in the TGA/DT and thermo-fluorination reactor were pressed in-house from 99.999\% nickel, as $0.254 \mathrm{~mm}$ thick sheet purchased from EPSI Metals (Ashland, OR) and were preconditioned by treatment with $\mathrm{NF}_{3}$ up to $610{ }^{\circ} \mathrm{C}$. Monel screens (400 mesh) were purchased from Cleveland Wire Cloth \& Mfg. Co (Cleveland, $\mathrm{OH}$ ).

Technetium-99 dioxide $\left({ }^{99} \mathrm{TcO}_{2}\right)$ was freshly prepared by thermal decomposition of $\mathrm{NH}_{4} \mathrm{TcO}_{4}$ (ref. 21) from house stocks at PNNL. Technetium-99 metal was prepared by heating ${ }^{99} \mathrm{TcO}_{2}$ in a thermo-gravimetric furnace in a gas stream of $4 \% \mathrm{H}_{2} / \mathrm{Ar}$ at $600{ }^{\circ} \mathrm{C}$. The resulting ${ }^{99} \mathrm{Tc}$ metal was a silver granular material. The metal was used in fluorination experiments immediately after each preparation.

For the mixed $\left[{ }^{99} \mathrm{Mo}\right] \mathrm{MoO}_{2} / \mathrm{UO}_{2}$ experiment, sodium molybdate and sodium borohydride were purchased from SigmaAldrich (St. Louis, MO) and used as received. No-carrier-added (NCA) ${ }^{99} \mathrm{Mo} /{ }^{99 \mathrm{~m}} \mathrm{Tc}$ solution in physiological saline solution was used as received from a commercial medical isotope supplier. A depleted uranium dioxide powder source from AREVA (Richland, WA) was used for the $\left[{ }^{99} \mathrm{Mo}\right] \mathrm{Mo} / \mathrm{UO}_{2}$ experiment.

\section{$2.2\left[{ }^{99} \mathrm{Mo}\right] \mathrm{MoO}_{2} / \mathrm{UO}_{2}$ sample preparation}

A homogeneous mixture of fine $\mathrm{UO}_{2}$ and $\left[{ }^{99} \mathrm{Mo}\right] \mathrm{MoO}_{2}$ crystals, in a $\sim 7.5: 1$ mole ratio, was prepared in a nickel pan. The sample was prepared via the following steps, with Table 1 summarizing the reagent inputs: sodium molybdate $\left(\mathrm{Na}_{2} \mathrm{MoO}_{4}\right)$ salt $(2.35 \mathrm{mg}$ ) was added to a microcentrifuge tube ("tube 1 "). A $0.76 \mathrm{~mL}$ aliquot of $\mathrm{NCA}^{99} \mathrm{Mo}(79.9 \pm 2.3 \mathrm{kBq}$, equivalent to 4.50 $\pm 0.13 \mathrm{pg}$ ) was added to the tube. The $\mathrm{Na}_{2} \mathrm{MoO}_{4}$ salts were allowed to completely dissolve and equilibrate in the tube, thus creating a homogeneous mixture of $\left[{ }^{99} \mathrm{Mo}\right] \mathrm{MoO}_{4}{ }^{2-}$ ions. In a separate microcentrifuge tube ("tube 2"), $\mathrm{NaBH}_{4}$ salts (12.43 $\mathrm{mg}$ ) were added and $0.2 \mathrm{~mL} \mathrm{H}_{2} \mathrm{O}$ was used to dissolve the salts. The resulting $\mathrm{NaBH}_{4}$ solution was added to tube 1 and the solutions were mixed thoroughly.

Precipitates of $\left[{ }^{99} \mathrm{Mo}\right] \mathrm{MoO}_{2}$ began to form quickly in the presence of the reducing agent. After several hours, it was determined that the $\mathrm{Mo}(\mathrm{vI}) \rightarrow \mathrm{Mo}(\mathrm{Iv})$ reduction was complete. Tube 1 was centrifuged at $\sim 8000 \mathrm{rpm}$ using Sorvall MC $12 \mathrm{~V}$ centrifuge (Dupont, Newtown, CT). Next, the supernate was removed. Water $(1 \mathrm{~mL})$ was added to tube 1 , and the $\left[{ }^{99} \mathrm{Mo}\right]$ $\mathrm{MoO}_{2}$ crystals were re-suspended. Depleted uranium dioxide powder $(23.05 \mathrm{mg})$ was added to the tube and the $\left[{ }^{99} \mathrm{Mo}\right] \mathrm{MoO}_{2} /$ $\mathrm{UO}_{2}$ mixture was thoroughly mixed by sonication. Tube 1 was again centrifuged and the supernate discarded. The mixture was re-suspended in $\sim 250 \mu \mathrm{L}$ water, and $50 \mu \mathrm{L}$ aliquots of the suspension were added to a Ni sample pan that had been placed under an infrared heat lamp. The solid suspension was quantitatively added to the pan in successive $\sim 50 \mu \mathrm{L}$ aliquots as the liquid in the pan was evaporated. Once thoroughly dried, the $\mathrm{Ni}$ pan containing the mixture of $\left[{ }^{99} \mathrm{Mo}\right] \mathrm{MoO}_{2}$ and $\mathrm{UO}_{2}$ was transferred to a thermo-fluorination apparatus for gas-phase $\left[{ }^{99} \mathrm{Mo}\right]$ Mo separation from $\mathrm{UO}_{2}$.

\subsection{Thermo-fluorination apparatus}

Thermogravimetric (TG) and differential thermal (DTA) screening data for the reaction of $\mathrm{NF}_{3}$ on samples of $\mathrm{UO}_{2}$, Mo and Tc metal, $\mathrm{MoO}_{2}$ and $\mathrm{TcO}_{2}$, and $\mathrm{MoO}_{3}$ (Fig. 1B) was acquired using a modified Seiko TG/DTA $320 .{ }^{12}$ The gases used for thermoanalytical experiments were $99.995 \%$ purity $\mathrm{NF}_{3}$ from Advanced Specialty Gases (Reno, NV) and 99.9995\% ultra-high purity (UHP) Ar from OXARC (Pasco, WA). The same instrument was used in the reduction of ${ }^{99} \mathrm{TcO}_{2}$ to ${ }^{99} \mathrm{Tc}$ metal, wherein a stream of $4 \% \mathrm{H}_{2}(99.99 \%)$ (OXARC) in Ar was used at $600{ }^{\circ} \mathrm{C}$ for $1 \mathrm{~h}$.

Modification of the TG/DTA system included conditions for adequate gas mixing and improvements for corrosion resistance. $\mathrm{NF}_{3} / \mathrm{UHP} \mathrm{Ar}$ gas mixtures were premixed in 4 linear feet of SS tubing ( 0.25 inch OD) prior to their entry into the furnace chamber of the TG apparatus. The premixed gas was routed through the analytical microbalance chamber by a 1/16 inch OD nickel tube to an area about $2.54 \mathrm{~cm}$ from the sample and 
Table 1 Reagent inputs for the formation of a homogeneous $\left[{ }^{99} \mathrm{Mo}\right] \mathrm{MoO}_{2} / \mathrm{UO}_{2}$ mixture

\begin{tabular}{lllll}
\hline Reagent & $\begin{array}{l}\text { Reagent mass, } \\
\text { mg }\end{array}$ & $\begin{array}{l}\text { Mass ratio, reagent: } \\
\mathrm{Na}_{2} \mathrm{MoO}_{4}\end{array}$ & Moles reagent & Mole ratio, reagent: $\left[{ }^{99} \mathrm{Mo}\right] \mathrm{MoO}{ }_{2}$ \\
\hline $\mathrm{Na}_{2} \mathrm{MoO}_{4}$ & $2.35^{a}$ & - & $1.14 \times 10^{-5} b$ & - \\
$\mathrm{NaBH}_{4}$ & 12.43 & 5.29 & $3.29 \times 10^{-4}$ & 28.8 \\
$\mathrm{UO}_{2}$ & 23.05 & 9.81 & $8.54 \times 10^{-5}$ & 7.48
\end{tabular}

${ }^{a}$ Dissolved salts spiked to $34.0 \pm 1.0 \mathrm{kBq}{ }^{99} \mathrm{Mo} / \mathrm{mg} \mathrm{Na} 2 \mathrm{MoO}_{4} \cdot{ }^{b}$ Equivalent to moles $\left[{ }^{99} \mathrm{Mo}\right] \mathrm{MoO}_{2}$ reaction product.

reference pans. This distance reduced buoyancy motion of the sample and reference arms as the dense gas mixture was released from the nickel tube and also allowed for some laminar flow of the gas mixture along the direction of the sample. A larger UHP Ar flow was passed though the analytical balance and sensitive electronic components to protect them from a backflow of hot $\mathrm{NF}_{3}$ and other reaction product gases. Three flow meters were used to adjust the $\mathrm{NF}_{3} / \mathrm{Ar}$ concentration to

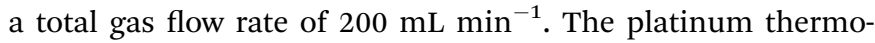
couples inside the balance beams were plated with nickel and the plating was covered in ceramic. The coatings help to reduce hot $\mathrm{NF}_{3}$ corrosion of the thermocouples for extended reaction screening of Mo, Tc and U samples, below $550{ }^{\circ} \mathrm{C}$. The coatings were supplied by RT Instruments (Woodland, CA).

\subsection{Fluorination protocol for $\left[{ }^{99} \mathrm{Mo}\right] \mathrm{MoO}_{2} / \mathrm{UO}_{2}$ samples}

The thermogravimetric apparatus described above was used to react the homogeneous $\left[{ }^{99} \mathrm{Mo}\right] \mathrm{MoO}_{2} / \mathrm{UO}_{2}$ mixture with $\mathrm{NF}_{3}$. Two sequential activated alumina traps were attached to the 0.75 inch output of the TG alumina furnace tube as shown in Fig. 1A. The traps were made of 0.75 inch o.d. Teflon ${ }^{\circledR}$ PFA tubing (McMaster-Carr, Chicago, IL) assembled with Swagelok (Solon, $\mathrm{OH})$ Teflon ${ }^{\circledR}$ PFA tube unions. The activated alumina spheres were contained in the tubing with the use of Monel screens placed within the tube unions; the spheres were slightly crushed to produce trap packing media that allowed unimpeded flow of gases. Behind the rear trap, a quartz wool plug was placed after the rear Monel screen. From there, a Teflon tube routed effluent gases through a $125 \mathrm{~mL}$ Erlenmeyer flask configured as a water bubbler.

At the end of a thermo-fluorination experiment, the traps and the furnace tube were disassembled, and each component was washed using a series of solvent washes as is described in detail below. The residual components in the nickel sample pan were fully analyzed by dissolution of the entire sample pan in nitric acid. The distribution of ${ }^{99}$ Mo was evaluated by gamma counting, and that of the $\mathrm{U}$ was evaluated by inductively coupled plasma-mass spectrometry (ICP-MS).

\subsection{Radiometric measurements}

1. HPGe: reference standards were prepared by spiking known volumes of ${ }^{99} \mathrm{Mo}$-bearing solutions (in secular equilibrium with ${ }^{99 \mathrm{~m}} \mathrm{Tc}$ ) into $2.0 \mathrm{~mL}$ of $0.1 \mathrm{M} \mathrm{HCl}$ in $20 \mathrm{~mL}$ glass scintillation vials. These samples were analyzed using several high purity germanium (HPGe) gamma detectors (Ortec, Oak Ridge, TN) that had been energy and efficiency calibrated for this geometry

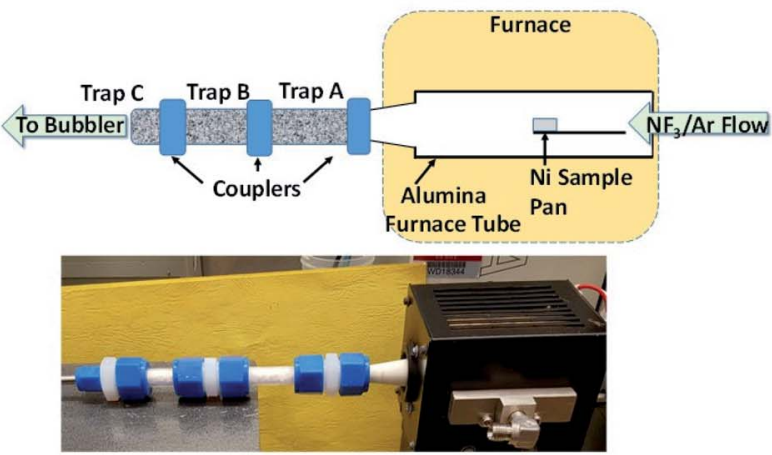

A

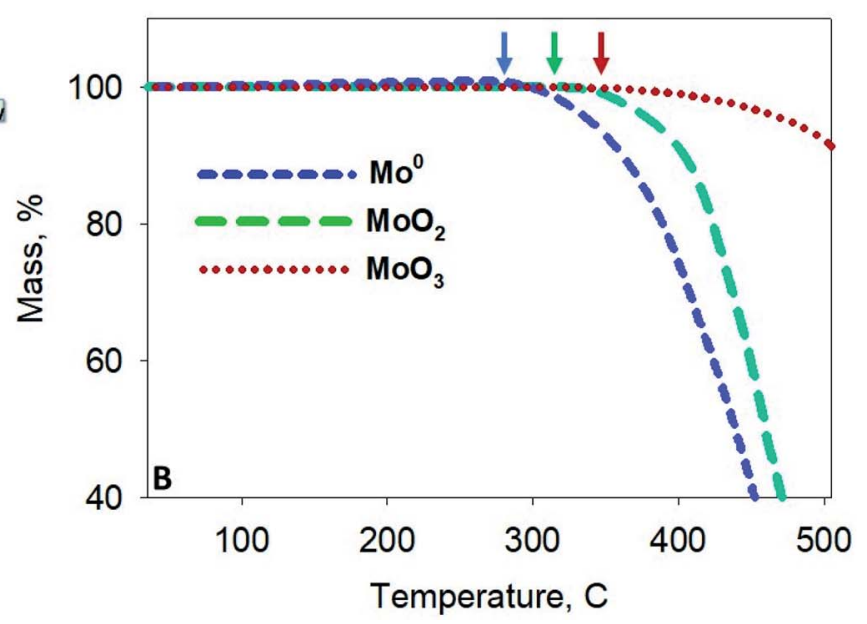

Fig. 1 (A) Schematic and image of the fluorination apparatus. Two packed alumina traps (Traps A and B) and a quartz wool (Trap C) were coupled to the furnace tube outlet. Effluent gases were scrubbed through a bubbler trap prior to release. (B) Thermogravimetric scans of $\mathrm{Mo}^{\circ}$ metal, $\mathrm{MoO}_{2}$, and $\mathrm{MoO}_{3}$ powders exposed to a $5 \% \mathrm{NF}_{3} / \mathrm{Ar}$ gas mixture. Arrows indicate the onset of volatility below $350{ }^{\circ} \mathrm{C}$. 

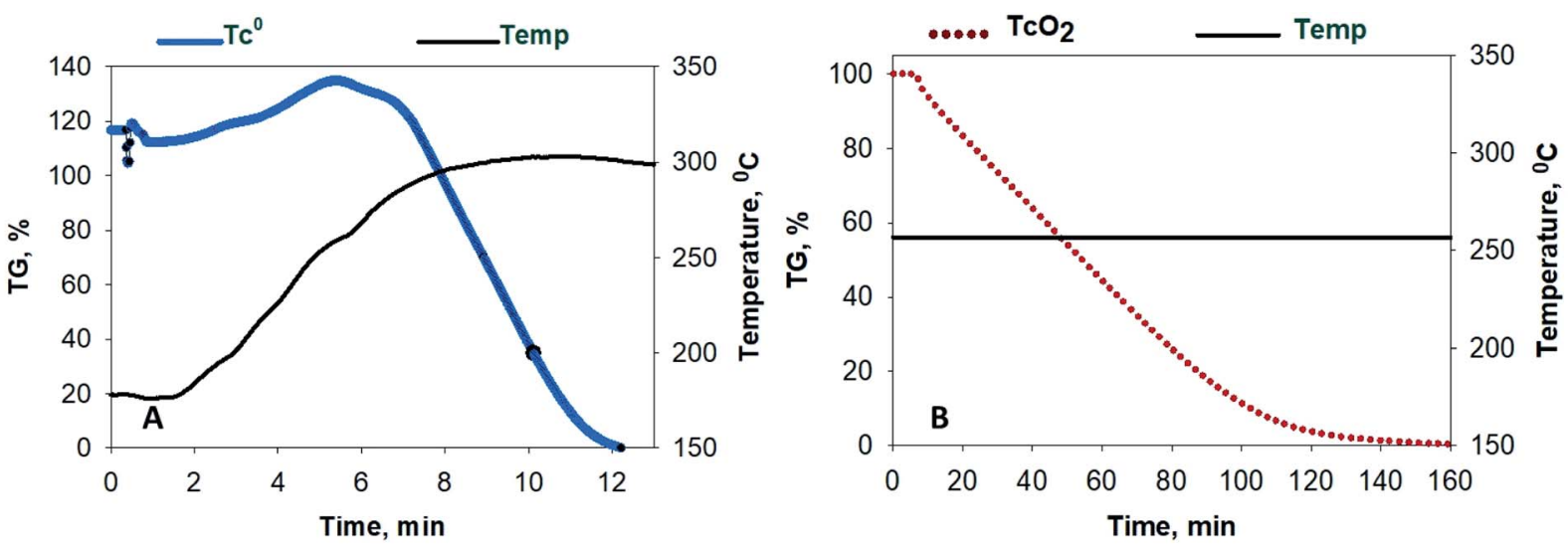

Fig. 2 Conversion of ${ }^{99} \mathrm{Tc}$ metal and ${ }^{99} \mathrm{TcO}_{2}$ to their volatile fluorides $\left({ }^{99} \mathrm{TcF}\right.$ ) by exposure to $5 \% \mathrm{NF}_{3}$ (in Ar). (A) Evolution of ${ }^{99} \mathrm{Tc}$ metal, which initiates at $\sim 180{ }^{\circ} \mathrm{C}$, and (B) ${ }^{99} \mathrm{TCO}_{2}$, which initiates at or below $\sim 250{ }^{\circ} \mathrm{C}$.

using NIST traceable standards. Gamma spectra were evaluated using Genie 2000 Gamma Acquisition and Analysis software (v. 3.4.1) (Canberra, Meriden, CT). The mean ${ }^{99}$ Mo activity obtained in the reference standards using the HPGe detector analysis was used to establish the various detection efficiencies $\left(E_{\mathrm{d}}\right)$ for ${ }^{99}$ Mo-bearing samples of non-standardized geometries using $\mathrm{NaI}(\mathrm{Tl})$ scintillation detectors (described below).

2. Auto-gamma counter: aqueous samples were prepared as $2.0 \mathrm{~mL}$ aliquots in $12 \times 74 \mathrm{~mm}$ test tubes for counting on a Wizard 1470 (PerkinElmer, Meriden, CT) automatic gamma counter containing a well-type $\mathrm{NaI}(\mathrm{Tl})$ scintillation detector. The detector was configured with a counting protocol specific to the ${ }^{99 \mathrm{~m}} \mathrm{Tc}$ gamma emission region of interest (corresponding to $140.57 \mathrm{keV}(89 \pm 4 \%$ intensity)). Samples were not analyzed until secular equilibrium between ${ }^{99} \mathrm{Mo}$ and ${ }^{99 \mathrm{~m}} \mathrm{Tc}$ was attained (sample analyses were performed $\sim 24 \mathrm{~h}$ after each experiment was conducted). The $E_{\mathrm{d}}$ for the Wizard 1470 was determined by comparing the count rate of a $2.0 \mathrm{~mL}$ aliquot of ${ }^{99} \mathrm{Mo} /{ }^{99 \mathrm{~m}} \mathrm{Tc}$ solution in the test tube $v s$. the $2.0 \mathrm{~mL}$ aliquot activity determined by the calibrated HPGe detector.

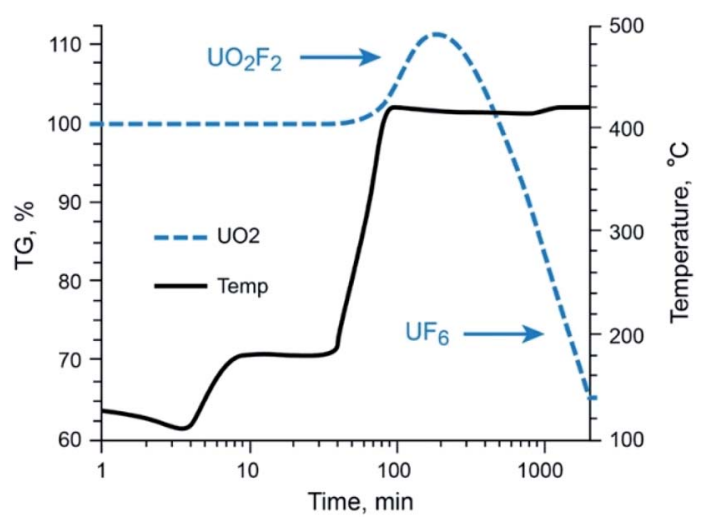

Fig. 3 Thermo-fluorination conversion of $\mathrm{UO}_{2}$ to $\mathrm{UO}_{2} \mathrm{~F}_{2}$ to $U \mathrm{~F}_{6(\mathrm{~g})}$ with $5 \% \mathrm{NF}_{3} . \mathrm{UO}_{2} \mathrm{~F}_{2}$ to $\mathrm{UF}_{6(\mathrm{~g})}$ conversion occurs at temperatures well above that required for volatile $\mathrm{MoF}_{6}{ }^{99} \mathrm{TcF}_{6}$ formation.
3. Benchtop NaI(Tl) detector/scaler: non-aqueous samples (e.g., sample pan, trap components, furnace tube) were counted using a Ludlum 2200 scaler/rate meter coupled to a $2^{\prime \prime}$ dia. $\mathrm{NaI}(\mathrm{Tl})$ scintillation detector (Sweetwater, TX). Sample observation distance was maximized to $\geq 15 \mathrm{~cm}$ to minimize geometry effects. At a given sample/detector distance, $E_{\mathrm{d}}$ was determined by comparing the $\mathrm{NaI}(\mathrm{Tl})$ detector count rate with that of the HPGe-analyzed standard as described above. Again, samples were not analyzed until secular equilibrium between ${ }^{99} \mathrm{Mo}$ and ${ }^{99 \mathrm{~m}} \mathrm{Tc}$ was attained.

\subsection{Mass spectrometric measurements}

After complete decay of ${ }^{99} \mathrm{Mo}$, dilutions of the dissolved $\mathrm{Ni}$ sample pan and trap leachates were prepared in $2 \%$ Optima grade $\mathrm{HNO}_{3}$. Quantification of $\mathrm{U}$ in the diluted solutions was performed by an Agilent 7700X (Ventura, CA) ICP-MS. Sample solutions were delivered to the mass spectrometer with a fluoride-resistant polyfluoroalkoxy alkane sample intake and nebulizer (Glass Expansion, Pocasset, MA). A ten-point calibration curve was prepared by gravimetric dilutions from a NIST traceable $1000 \mathrm{ppm}$ single element U standard obtained from

Table 2 Distribution of molybdenum and uranium following thermofluorination of $\left[{ }^{99} \mathrm{Mo}\right] \mathrm{MoO}_{2} / \mathrm{UO}_{2}$ mixture

\begin{tabular}{lcl}
\hline & \multicolumn{2}{c}{ Isotope \& elemental distribution } \\
\cline { 2 - 3 } Component $^{a}$ & {$\left[{ }^{99} \mathrm{Mo}\right] \mathrm{Mo}, \%$} & $\mathrm{U}, \%$ \\
\hline Post-fluorinated pan & 4.34 & $95.3 \pm 3.4$ \\
Furnace tube & 9.71 & $0.024 \pm 0.001$ \\
Trap A & 71.38 & $<0.001$ \\
Trap B & 0.42 & $<0.001$ \\
Trap C & 0.39 & $0.002 \pm 0.001$ \\
Bubbler trap & 0.01 & $0.118 \pm 0.004$ \\
Total yield & 86.26 & $95.5 \pm 3.4$
\end{tabular}

${ }^{a}$ See Fig. 1 for component locations. 
High Purity Standards (Charleston, SC). The calibration curve had a regression coefficient of 0.9999 .

\section{Results and discussion}

\subsection{Evaluation of $\mathrm{Mo}, \mathrm{Tc}$, and $\mathrm{UO}_{2}$ volatility by fluorination}

Fluoride volatility of Tc was likewise evaluated under the same conditions. Fig. 2A shows the evolution of ${ }^{99} \mathrm{TcF}_{6}$ from ${ }^{99} \mathrm{Tc}$ metal, which initiates at $\sim 180{ }^{\circ} \mathrm{C}$, and that from ${ }^{99} \mathrm{TcO}_{2}$, which initiates at or below $\sim 250{ }^{\circ} \mathrm{C}$ isothermal in Fig. $2 \mathrm{~B}$. The volatile reaction products are analogous to the Mo complexes discussed above. In Fig. 1B and $2 \mathrm{~A}$ and B, the volatile species of Mo and Tc were removed from the reaction system by the Ar gas purge as demonstrated by the steep downward slopes of the TG scans. The Mo and Tc volatility profiles were found to be quite similar, and the complete removal of $\mathrm{Te}, \mathrm{Ru}, \mathrm{Nb}, \mathrm{Sb}$, and several other elements have been shown previously to follow suit. ${ }^{17,18}$

The behavior of $\mathrm{UO}_{2}$ with exposure to $\mathrm{NF}_{3}$ provides a stark contrast to that observed with Mo and Tc species, as shown in Fig. 3. Fluorination of $\mathrm{UO}_{2}$ is quite unique to this oxide of $\mathrm{U}$ and has been described previously by members of this research team. ${ }^{12}$ Using the same $5 \% \mathrm{NF}_{3} / \mathrm{Ar}$ mixture employed for Moand Tc-bearing materials, $\mathrm{UO}_{2}$ was converted to non-volatile $\mathrm{UO}_{2} \mathrm{~F}_{2}$ once the temperature approached $420{ }^{\circ} \mathrm{C}$, after which a plateau region was sustained for several hours with the proper $\mathrm{NF}_{3}$ exposure conditions before significant production of gaseous $\mathrm{UF}_{6}$ occurred. The thermogravimetric evaluations with gas streams of heated $5 \% \mathrm{NF}_{3} / \mathrm{Ar}$ indicate that gas-phase separations of $\mathrm{Mo}$ (metal and $\mathrm{MoO}_{2}$ ) and $\mathrm{Tc}$ (metal and $\mathrm{TcO}_{2}$ ) from $\mathrm{UO}_{2}$ is feasible.

Gaseous fluorides of these transition metals can be generated at temperatures below the conversion temperature of $\mathrm{UO}_{2}$ to $\mathrm{UF}_{6}$ (via $\mathrm{UO}_{2} \mathrm{~F}_{2}$ formation). This permits $\mathrm{NF}_{3}$ leaching of a fissioned $\mathrm{UO}_{2}$ solid with no $\mathrm{UF}_{6}$ attendant in the gaseous Mo (Tc) phase.

\subsection{Gas-phase separation of $\left[{ }^{99} \mathrm{Mo}\right] \mathrm{MoO}_{2}$ from $\mathrm{UO}_{2}$}

Given the preceding thermogravimetric results for metal and metal oxide constituents and $\mathrm{UO}_{2}$, a gas-phase separation of ${ }^{99} \mathrm{Mo}\left(\right.$ as $\mathrm{MoO}_{2}$ ) from $\mathrm{UO}_{2}$ was evaluated. A sample was prepared in a nickel sample pan that consisted of a homogeneous mixture of fine $\mathrm{UO}_{2}(23 \mathrm{mg})$ and $\mathrm{MoO}_{2}$ crystals $(1.5 \mathrm{mg}) ; \mathrm{NaBH}_{4}$ was initially used to reduce an aqueous solution of $\mathrm{Na}_{2}\left[{ }^{99} \mathrm{Mo}\right]$ $\mathrm{MoO}_{4}$ to form a composite isotope solid of $\left[{ }^{99} \mathrm{Mo}\right] \mathrm{MoO}_{2}$ via eqn $(5) .{ }^{22}$

$$
\begin{aligned}
\mathrm{Na}_{2} \mathrm{MoO}_{4}+\mathrm{NaBH}_{4}+\underset{2}{2} \mathrm{H}_{2} \mathrm{O} \rightarrow \\
\qquad \mathrm{NaO}_{2}+\mathrm{MoO}_{2}+2 \mathrm{NaOH}+3 \mathrm{H}_{2}
\end{aligned}
$$

For this experiment, the outlet of the modified TG furnace tube was connected to tandem traps (A and B) that were packed with activated alumina. A third trap (C) was packed with a compact bundle of quartz wool (Fig. 1A). A fluorination experiment was performed with a $5 \% \mathrm{NF}_{3} / \mathrm{Ar}$ mixture, and the furnace temperature held at $\sim 400{ }^{\circ} \mathrm{C}$ for $2 \mathrm{~h}$. At the end of the experiment, the trapping system components were disconnected from the furnace tube, and each of the three traps was disconnected from each other. Next, each component in Fig. 1A was leached using a series of solvent washes. These washes included that of the furnace tube and each of the three traps. The nickel sample pan (and salt residues) was completely dissolved in nitric acid. The water in the bubbler trap was acidified and evaporated to near dryness. Each component and wash solution was analyzed by gamma counting $\left({ }^{99} \mathrm{Mo} /{ }^{99 m} \mathrm{Tc}\right)$ and ICP-MS (U).

Analysis of the distribution of $\left[{ }^{99} \mathrm{Mo}\right] \mathrm{Mo}$ and $\mathrm{U}$ revealed an excellent separation of the fission product from the simulated fissioned source material. The Mo was almost completely removed from the sample pan, with only $4 \%$ remaining (Table 2). Approximately $10 \%$ was deposited on the walls of the furnace tube, and $71 \%$ was captured in Trap A. Less than 1\% of Mo was measured in Traps B, C, and the bubbler. In total, $86 \%$ of the Mo was accounted for in the assays of the trapping components. Of the Mo captured in Trap A, $\sim 70 \%$ was removed with a $5 \mathrm{~mL}$ $\mathrm{H}_{2} \mathrm{O}$ rinse (representing $\sim 50 \%$ of the total Mo pan deposit), and an additional $21 \%$ was recovered in two sequential washes with $\mathrm{NaOH}$ (Table 3). Within the three Trap A aqueous washes, $\sim 65 \%$ of the pan-deposited Mo was recovered.

Radiometric counting of the trapping components immediately after disassembly (before ${ }^{99} \mathrm{Mo} /{ }^{99 m} \mathrm{Tc}$ secular equilibrium was attained) provided qualitative indication that ${ }^{99 \mathrm{~m}_{\mathrm{m}}}$ Tc was transported efficiently out of the pan and was successfully deposited primarily in the furnace tube and Trap A. Unfortunately, quantitative determination of the ${ }^{99 \mathrm{~m}} \mathrm{Tc}$ depositions were not possible with the use of the $\mathrm{NaI}(\mathrm{Tl})$ scintillation detector/scaler. However, an HPGe detector scan of the post-reacted Ni sample pan indicated that ${ }^{99 \mathrm{~m}} \mathrm{Tc}$ was successfully volatilized and transported out of the pan, thereby corroborating the observed volatilization profile shown in Fig. 2.

Table 3 Distribution of $\left[{ }^{99} \mathrm{Mo}\right] \mathrm{Mo}$ recovered from Traps A and B using a multi-step aqueous recovery method

\begin{tabular}{lllll}
\hline Treatment & Reagent & Volume, mL & Trap A recovery ${ }^{a}, \%$ & Trap B recovery $^{b}, \%$ \\
\hline Elute 1 & $\mathrm{H}_{2} \mathrm{O}$ & 5 & 69.8 & 55.0 \\
Elute 2 & $4 \mathrm{M} \mathrm{NaOH}$ & 5 & 17.0 & $7.6^{c}$ \\
Elute 3 & $4 \mathrm{M} \mathrm{NaOH}$ & 5 & 4.0 & - \\
$\mathrm{Al}_{2} \mathrm{O}_{3}$ leach & $4 \mathrm{M} \mathrm{NaOH}, \Delta^{d}$ & 5 & 5.7 & 23.5 \\
$\mathrm{Al}_{2} \mathrm{O}_{3}$ residue & - & - & 3.4 & 13.9
\end{tabular}

${ }^{a}$ Total recovered ${ }^{99}$ Mo activity fraction $=71.38 \%$ (from Table 2). ${ }^{b}$ Total recovered ${ }^{99}$ Mo activity fraction $=0.42 \%$ (from Table 2 ). ${ }^{c}$ Elutes 2 and 3 were combined into single vessel. ${ }^{d} \mathrm{Al}_{2} \mathrm{O}_{3}$ in traps emptied into vessel followed by hot leaching with $\mathrm{NaOH}$; leachate assayed for ${ }^{99} \mathrm{Mo}$ activity. 
In sharp contrast, the $\mathrm{U}$ remained in a non-volatile state; 95.3 $\pm 3.4 \%$ of the original $U$ deposit remained in the nickel sample pan, and $\sim 0.027 \%$ was found in the furnace tube $(0.024 \%)$ and the three traps $(0.003 \%$, Table 2$)$. Based on the mass of $U$ measured in the combined trap leaches, the $\mathrm{U}$ decontamination factor in the Trap A $\left[{ }^{99} \mathrm{Mo}\right]$ Mo product was $>1.0 \times 10^{5}$. Total $\mathrm{U}$ recovery in all fractions was found to be $95.5 \pm 3.2 \%$, a value that was within the analytical uncertainty of the experiment.

\section{Conclusions}

We show that exposure of a homogeneous mixture of $\left[{ }^{99} \mathrm{Mo}\right] \mathrm{Mo} /$ $\mathrm{UO}_{2}$ to $5 \% \mathrm{NF}_{3} / \mathrm{Ar}$ mixture at $\sim 400{ }^{\circ} \mathrm{C}$ for $\sim 2 \mathrm{~h}$ results in a rapid, high yield extraction of $\left[{ }^{99} \mathrm{Mo}\right]$ Mo from $\mathrm{U}$.

Of the $\sim 86 \%$ of ${ }^{99}$ Mo activity accounted for in the various furnace/trap components, $\sim 71 \%$ of the ${ }^{99}$ Mo activity was deposited in the first alumina trap. A simple $5 \mathrm{~mL}$ water wash of the trap's alumina bed resulted in $\sim 70 \%$ of the trapped ${ }^{99} \mathrm{Mo}$ activity removal, which represented $\sim 50 \%$ of the total ${ }^{99} \mathrm{Mo}$ activity originally deposited in the nickel pan. Technetium-99m was likewise transported and collected on the alumina trap with the separated ${ }^{99}$ Mo product, although quantitative distribution was not possible in this first test. The results indicate that the gas-phase $\left[{ }^{99} \mathrm{Mo}\right] \mathrm{Mo}$ product was largely devoid of $\mathrm{U}$ contamination.

Aqueous processing releases I, Te, Xe and $\mathrm{Kr}$ potentially at every step of processing of irradiated targets. Acid dissolution, in particular promotes, volatile behavior in several elements as $\mathrm{Tc}$, and Ru. While fluoride volatility must release these species as well, we believe that the front-end processing of irradiated uranium targets by volatility-based separations is better suited by its rigorous closed engineering to sequester radionuclide populations than the digest and back end, clean-up approach historically and currently used by most nuclear-related enterprises. Fluoride volatility separations of ${ }^{99} \mathrm{Mo}$ from uranium, so described, has a sound chemical basis. Its practical implementation for radiopharmaceutical scale processing still requires elucidation of transport and capture technologies that are optimized for high efficiency retention of isotopes of pharmaceutical interest.

\section{Conflicts of interest}

There are no conflicts to declare.

\section{Acknowledgements}

This work was performed at Pacific Northwest National Laboratory. The Pacific Northwest National Laboratory is operated for the U.S. Department of Energy by Battelle under contract DEAC06-67RLO 1830.

\section{References}

1 R. M. Ball, Characteristics of nuclear reactors used for the production of molybdenum-99, Production Technologies for
Molybdenum-99 and Technetium-99m, IAEA-TECDOC-1065, International Atomic Energy Agency, Vienna, 1999, pp. 5-17.

2 G. F. Vandegrift and J. L. Snelgrove, et al., Converting targets and processes for fission-product molybdenum-99 from high- to low-enriched uranium, Production Technologies for Molybdenum-99 and Technetium-99m, IAEA-TECDOC-1065, International Atomic Energy Agency, Vienna, 1999, pp. 2574.

3 G. F. Vandegrift, C. Conner, G. L. Hofman, R. A. Leonard, A. Mutalib, J. Sedlet, D. E. Walker, T. C. Wiencek and J. L. Snelgrove, Modification of Targets and Processes for Conversion of ${ }^{99} \mathrm{Mo}$ Production from High- to LowEnriched Uranium, Ind. Eng. Chem. Res., 2000, 39(9), 31403145 .

4 H. Kobayashi, O. Amano, et al., FLUOREX reprocessing system for the thermal reactors cycle and future thermal/ fast reactors (coexistence) cycle, Prog. Nucl. Energy, 2005, 47(1), 380-388.

$5 \mathrm{~J}$. Uhlir, An experience on dry nuclear fuel reprocessing in the Czech Republic, in 5th International Information Exchange Meeting on Actinide and Fission Product Partitioning and Transmutation, Czech Republic, 1999.

6 V. K. Ezhov, Commercial rectification facility for deep purification of sublimate uranium hexafluoride, At. Energ., 2007, 103(5), 890-894.

7 A. A. Jonke, Reprocessing of Nuclear Reactor Fuels by Processes Based on Volatilization Fractional Distillation, and Selective Adsorption, At. Energy Rev., 1965, 3, 3-60.

8 A. A. Jonke, N. M. Levitz and M. J. Steindler, The potential of the fluoride volatility process for fast breeder reactor fuels, in Symposium on Reprocessing of Nuclear Fuels, The Metallurgical Society and Ames Laboratory, Ames, IA, 1969.

9 N. M. Levitz, A Conceptual Design Study of a Fluoride-Volatility Plant for Reprocessing LMFBR Fuels. ANL-7583, Argonne National Laboratory, Argonne, IL, 1969, p. 295.

10 W. H. Carr., L. J. King, F. G. Kitts, W. T. McDuffee and F. W. Miles, Molten-Salt Fluoride Volatility Pilot Plant: Recovery of Enriched Uranium from Aluminum-Clad Fuel Elements, ORNL-4574, Oak Ridge National Laboratory, Oak Ridge, TN, 1971, p. 82.

11 W. L. Carter and M. E. Whatley, Fuel and Blanket Processing Development for Molten Salt Breeder Reactors, ORNL-TM1852, Oak Ridge National Laboratory, Oak Ridge, TN, 1967, p. 52 .

12 B. K. McNamara, M. J. O'Hara, A. M. Casella, J. C. Carter, R. S. Addelman and P. J. MacFarlan, Uniform deposition of uranium hexafluoride $\left(\mathrm{UF}_{6}\right)$ : Standardized mass deposits and controlled isotopic ratios using a thermal fluorination method, Talanta, 2016, 154, 219-227.

13 B. K. McNamara, R. D. Scheele, A. M. Casella, A. E. Kozelisky and D. Neiner, Fluorination of Uranium Metal to $\mathrm{UF}_{3}$ and $\mathrm{UF}_{4}$ by Nitrogen Trifluoride: Evidence for Elusive $\mathrm{UF}_{2}$, Mater. Res. Soc. Symp. Proc., 2010, 1264, 1264-Z06-03, DOI: 10.1557/PROC-1264-Z06-03.

14 D. Watanabe, A. Sasahira, K. Hoshino and F. Kawawamura, Adsorption of Molybdenum Hexafluoride on Magnesium 
Difluoride for Uranium Purification in FLUOREX Reprocessing, J. Nucl. Sci. Technol., 2011, 48(12), 1413-1419. 15 R. Jubin, Used Fuel Reprocessing, in Nuclear Fuel Cycle Course, Consortium for Risk Evaluation with Stakeholder Participation (CRESP): Fuel Cycle and Isotopes Division, Oak Ridge National Laboratory, 2011.

16 R. A. Clark, B. K. McNamara, C. J. Barinaga, J. M. Peterson, N. Govind, A. Andersen, D. G. Abrecht, J. M. Schwantes and N. E. Ballou, Electron ionization mass spectrum of tellurium hexafluoride, Inorg. Chem., 2015, 54(10), 48214826.

17 R. D. Scheele, B. K. McNamara, A. M. Casella and A. E. Kozelisky, On the use of thermal $\mathrm{NF}_{3}$ as the fluorination and oxidation agent in treatment of used nuclear fuels, J. Nucl. Mater., 2012, 424(1-3), 224-236.
18 B. K. McNamara, E. C. Buck, C. Z. Soderquist, F. N. Smith, E. J. Mausolf and R. D. Scheele, Separation of metallic residues from the dissolution of a high-burnup BWR fuel using nitrogen trifluoride, J. Fluorine Chem., 2014, 162, 1-8.

19 T. R. Mills and L. W. Reese, Separation of plutonium and americium by low-temperature fluorination, $J$. Alloys Compd., 1994, 213, 360-362.

20 D. Brown, Halides of the Lanthanides and Actinides, in Halides of the Transition Elements, Wiley, New York, 1968.

21 P. P. Chinenov, S. I. Rovnyi, V. V. Ershov and V. A. Mezentsev, Production of technetium preparations of high radiochemical purity, At. Energ., 1996, 81(1), 467-470.

22 C. F. Tsang and A. Manthiram, Synthesis of lower-valent molybdenum oxides in aqueous solutions by reducing $\mathrm{Na}_{2} \mathrm{MoO}_{4}$ with $\mathrm{NaBH}_{4}$, J. Mater. Chem., 1997, 7(6), 10031006. 